\title{
Memórias juvenis: a influência do cinema no cotidiano dos jovens nos anos 60
}

\section{RESUMO}

O artigo tem como objetivo desenvolver uma possibilidade de metodologia para investigações que tenham como premissa verificar a influência do cinema no comportamento dos jovens, considerando conceitos como: cotidiano, lazer e memória. Para refletir sobre a problemática foi utilizada como fonte a mídia impressa e as fontes orais. Para exemplificar a análise escolhemos a cidade de Novo Hamburgo, na década de 60. Foi utilizada a análise de conteúdo para verificamos a presença do cinema na localidade. Esses dados subsidiaram a construção das entrevistas que foram elaboradas por intermédio da História Oral. Essa proximidade com as "vozes" dos depoentes nos possibilitou acesso às memórias dessas pessoas que eram jovens na década de 60, que relataram como o cenário cinematográfico influenciou a juventude daquela época.

\section{PALAVRAS-CHAVE}

cotidiano

lazer

memória

\section{ABSTRACT}

The text aims to develop a viable methodology for researches that have as a conjecture the verification of the influence of cinema in the behavior of young people, taking into account concepts as: daily life, leisure and memory. To reflect the theme's problematization print media and oral sources were used. To exemplify the analysis we chose the city of Novo Hamburgo in the sixties. Content analysis was used to verify the relevance of cinema in the city. These data subsidized the construction of interviews that were elaborated through oral history postulates. This proximity with the "voices" of the individuals allowed access to these person's memories that were young in the sixties, that described how the cinematographic scene shaped the youth of those days.

\section{KEY WORDS}

leisure

memory

daily life

\section{Paula Regina Puhl \\ Professora do Curso de Comunicação da Feevale, Novo Hamburgo/RS/BR ppuhl@feevale.br}

\section{Cristina Ennes da Silva}

Presidente do Conselho de Pesquisa e Pós-Graduação Stricto Senso da Feevale, Novo Hamburgo/RS/BR

crisennes@feevale.br
Neste estudo utilizamos como categorias de análise: o cotidiano, - lazer e a memória, articulando-os com o eixo central da investigação, ou seja, com o cinema e como este influenciou o comportamento dos jovens na década de 60, em Novo Hamburgo. Neste sentido sobressai a fala de Heller (2000, p.17), no tocante à vida cotidiana quando esta a define como sendo a "vida de todo homem. Todos a vivem, sem nenhuma exceção", visto que, intrinsecamente contêm as práticas, os sentidos, as habilidades, as ideias e os sentimentos do homem e, por isso, fazem parte dela a organização do trabalho e da vida privada, os lazeres e o descanso, a atividade social e sistematizada e o intercâmbio.

\section{O lazer vinculado ao hábito de ir ao cinema, mesmo que partindo de um movimento individual, permite que a memória seja (re)construída a partir de parâmetros coletivos.}

O lazer está inserido, portanto, como parte do cotidiano tendo seus fazeres atrelados aos elementos componentes do dia-a-dia, mesmo que não se efetive em todos os momentos. Esta percepção é balizada por Dumazedier (1979, p.94) que postula o lazer como sendo,

o conjunto de ocupações às quais o indivíduo pode entregar-se de livre vontade, seja para repousar, seja para divertir-se, recrear-se e entreter-se, ou, ainda, para desenvolver sua informação ou formação desinteressada, sua participação social voluntária ou sua livre capacidade criadora, após livrar-se das obrigações profissionais, familiares e sociais.

Assim, o exercício cotidiano do lazer sugere um "novo equilíbrio entre as exigências utilitárias da sociedade e as exigências desinteressadas da pessoa". (Dumazedier, 1979, p.59), assim, se institui e justifica na busca por um estado de satisfação, através da procura do prazer, felicidade ou alegria. Sob esta perspectiva o lazer constitui-se, portanto, elemento fundamental do cotidiano do indivíduo.

Neste contexto, a memória se apresenta como elemento essencial para a percepção do cotidiano onde o lazer 
tem sua realização, pois concordamos com as concepções de Halbwachs (2006), que indica que a memória individual existe sempre a partir de uma memória coletiva, a partir do local ocupado pelo sujeito no interior do grupo e das relações mantidas com outros meios, pois,

os fatos e idéias que mais facilmente recordamos são do terreno comum, pelo menos para um ou alguns ambientes. Essas lembranças existem para "todo o mundo" nesta medida e é porque podemos nos apoiar na memória dos outros que somos capazes de recordá-las a qualquer momento e quando o desejamos (Halbwachs, 2006, p.66-67).

Assim, o lazer vinculado ao hábito de ir ao cinema, mesmo que partindo de um movimento individual, permite que a memória seja (re)construída a partir de parâmetros coletivos. Os elementos motivadores da lembrança estarão, neste caso, associados mais a fatores externos e significativos para todo o grupo, como, por exemplo, um determinado filme de sucesso, do que fatores predominantemente pessoais. Neste caso, nos reportamos novamente aos estudos de Halbwachs (2006) quando este indica que a memória liga-se à lembrança das vivências, e, assim, só existe quando laços criam o pertencimento ao grupo e ainda os mantém no presente. São precisamente estes laços que mantêm a vida no campo das lembranças comuns, gerando uma memória social.

\section{Uma análise do comportamento dos jovens a partir do cinema}

A nossa proposta de análise desse artigo é verificar a influência do cinema no comportamento dos jovens no início da década de 1960, em Novo Hamburgo ${ }^{1}$. O estudo analisa a importância deste para a população jovem da cidade, a fim de compreender a influência da cultura cinematográfica no comportamento desses jovens. Para isso foram pesquisadas as edições do jornal NH no período de 1960-1965 e também foram feitas entrevistas com pessoas que vivenciaram o período escolhido. A técnica de análise de conteúdo foi utilizada para analisar as reportagens enquanto que as entrevistas seguiram as premissas da história oral ${ }^{2}$.

Novo Hamburgo, local escolhido para a análise, teve sua origem associada à imigração alemã do início do século XIX. Na segunda metade do século seguinte, caracterizava-se por ser uma próspera cidade, com uma população que girava em torno de 70 mil habitantes com desenvolvimento econômico ligado à indústria do calçado, ramo conhecido como "setor coureirocalçadista".

Para atingir os objetivos, em um primeiro momento, foram utilizadas como fonte de pesquisa as colunas e comentários sobre cinema publicados no Jornal NH entre os anos de 1960 e 1965. Após a categorização e análise dos eventos publicados no jornal local, nossa pesquisa se direcionou na obtenção de depoimentos, através de entrevistas de história oral, para reconstruir aspectos da memória dos frequentadores dos cinemas.

O início da investigação pelo jornal é justificado por Wolf (2001) e Traquina (1999) que acreditam que a notícia atua sobre a construção da realidade social. $\mathrm{O}$ autor defende que as comunicações tendem a influenciar o modo como o leitor organiza a sua imagem em relação ao ambiente que o cerca. Ele escreve que no centro da problemática dos efeitos está "a relação entre a acção constante dos mass media e o conjunto de conhecimentos acerca da realidade social, que dá forma a uma determinada cultura e sobre ela age, dinamicamente" (Wolf, 2001, p.143).

Já Traquina (1999, p.253) se referir às notícias como estórias que são encaradas como uma construção. Elas ajudam a compreender os valores e os símbolos de uma determinada cultura. Em relação a uma análise da influência das mídias, o autor diz que a força "não está só no seu poder de declarar as coisas como sendo verdadeiras, mas no seu poder de fornecer as formas nas quais as declarações aparecem".

A escolha do Jornal NH, constitui-se como fonte de pesquisa privilegiada para este estudo, pois, no período abordado, era um dos principais meios de comunicação e informação, não só da cidade de Novo Hamburgo, como também da região. Durante o período pesquisado, o jornal era semanal e não possuía uma diagramação fixa, assim os locais para a divulgação da programação dos cinemas ou ainda a coluna do Cine Clube de Novo Hamburgo ocupavam páginas diferentes em cada edição.

Para coletar e analisar as fontes empíricas recorreu-se a Bardin (1977), por intermédio da técnica de análise de conteúdo, que está organizada em três fases: a leitura flutuante e a pré-análise, a exploração do material e o tratamento dos resultados, inferência e interpretação.

A nossa pré-análise se constituiu na escolha do material a ser analisado. Para isso foram selecionados os anos de 1960 a 1965, por serem os primeiros anos da publicação do Jornal NH. A escolha é justificada pelo fato de a cidade de Novo Hamburgo possuía muitas salas de cinema na época e ir ao cinema, conforme comprovado mais tarde, constituía uma das principais atividades de lazer da população. Assim, elaboramos a hipótese de que os filmes exerciam uma influência sobre as pessoas que frequentavam as salas de cinema.

$\mathrm{Na}$ fase sobre a exploração do material que Bardin (1977) que corresponde a uma transformação de dados brutos do texto, foram fotografadas em um primeiro momento todas as aparições sobre cinema no jornal. Já na fase do tratamento dos resultados, essas matérias fotografadas foram separadas por categorias, criamos índices e organizamos o material, para então passarmos para a interpretação das informações. 
Logo após a análise de conteúdo das matérias, sentimos a necessidade de aprofundar algumas questões relativas aos jovens daquela época. A leitura e a análise das matérias colaboraram para a construção do roteiro de perguntas para as entrevistas. Optamos pelo uso da História Oral por constituir-se de uma fonte de pesquisa para o estudo da história recente, que contanos sobre muito que não está nos livros. Baseamo-nos em Alberti (2005, p.164), que afirma: "a história oral é hoje um caminho interessante para se conhecer e registrar múltiplas possibilidades que se manifestam e dão sentido a formas de vida e escolhas de diferentes grupos sociais, em todas as camadas da sociedade".

Assim, seguimos o método de Alberti (2005) que está organizado em três momentos: a preparação das entrevistas, a sua realização e o seu tratamento. A fase de preparação das entrevistas, segundo Alberti (2005), inclui o projeto de pesquisa e a elaboração do roteiro, além da definição do perfil dos entrevistados. Nesta investigação preparamos o roteiro de perguntas, que girava em torno do questionamento "Você frequentava as salas de cinema em Novo Hamburgo em sua juventude?". As pessoas selecionadas para as entrevistas eram de diferentes classes sociais e sexo, que na década de 60 residiam na cidade e costumam ir ao cinema.

Entre elas estavam sete mulheres, com profissões de costureira, contabilista, dona de casa, lojista e professora. Foram entrevistados dois homens frequentadores dos cinemas, um jornalista e um fotógrafo, e um homem que era herdeiro do cinema Saionara e havia trabalhado no local.

\section{A relação entre as cidades e o cinema geralmente é caracterizada como uma prática de lazer e divertimento.}

Optamos por entrevistas temáticas, que para Alberti (2005) têm foco na participação do entrevistado no tema escolhido. As entrevistas foram realizadas após ampla investigação nas fontes impressas, tendo em vista a preparação de roteiros de entrevista, foram feitas perguntas amplas, para que os entrevistados se expressassem livremente acerca das questões propostas.

\section{Tratamento e análise do material impresso e a relação com a História Oral}

No período de 1960 a 1965, Novo Hamburgo possuía quatro salas de cinema, denominadas Aida, Avenida, Carlos Gomes (posteriormente Saionara) e Lumiere. Após este período, os locais começaram a entrar em decadência, conforme Selbach (1999, p.123) "gradual-

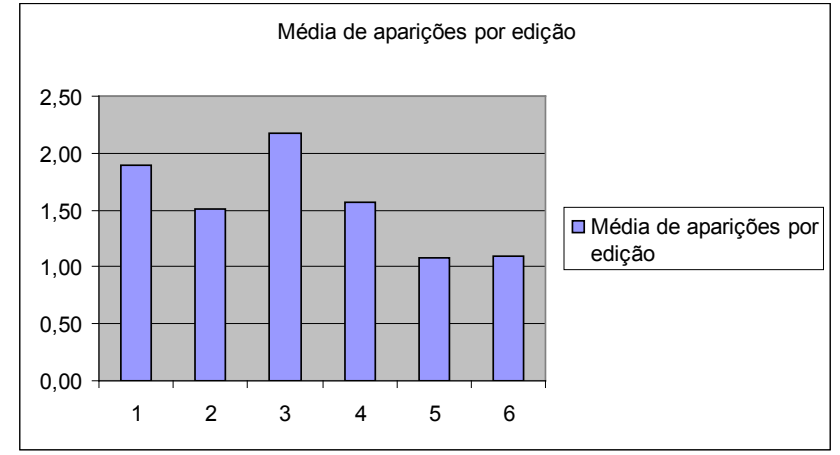

GRÁFICO I - Média de aparições sobre cinema por edição

Categorias

Programação dos cinemas

Propaganda de filmes

Cine Clube

Outros eventos

Total

$\begin{array}{cccccccc}1960 & 1961 & 1962 & 1963 & 1964 & 1965 & \text { Total } \\ 60 & 55 & 58 & 57 & 50 & 50 & 330 \\ 2 & 2 & 33 & 8 & 1 & 4 & 50 \\ 10 & 17 & 30 & 7 & 1 & 0 & 65 \\ 2 & 0 & 3 & 13 & 3 & 7 & 28 \\ 74 & 74 & 124 & 85 & 55 & 61 & 473\end{array}$

mente, o cinema entraria em decadência, pois o novo hamburguense preferiria ficar em casa a assistir algum filme". O surgimento da televisão e do videocassete teve, também, uma influência direta sobre a frequência dos hamburguenses ao cinema.

Foram pesquisadas todas as 306 edições do Jornal $\mathrm{NH}$, entre 1960 e 1965, época de ouro do cinema na localidade. Nestas, identificamos que os eventos relacionados ao cinema estiveram presentes em todas as edições do jornal e totalizaram um número de 437 aparições, com uma média de 79 por ano e 1,5 por edição.

Conforme o gráfico I, o número de eventos relacionados ao cinema veiculados no jornal foi bem representativo. Por isso, foi necessário fazer uma seleção do material, e logo após, dividi-lo em categorias, que levaram em conta o tipo de notícia vinculada à temática central (ao cinema), buscando subdividi-las conforme as informações presentes em cada aparição.

Com os resultados quantitativos obtidos, foi visto que ocorreu mais repetição no que se referiu a programação dos cinemas, enquanto que as notas do Cine Clube foram também frequentes, seguidas pelas propagandas de filmes.

A relação entre as cidades e o cinema geralmente é caracterizada como uma prática de lazer e divertimento. No caso de Novo Hamburgo, nos anos 60, o cinema esteve sempre muito presente, seja pelo número de salas de projeção, ou pelas atividades do Cine Clube Novo Hamburgo, responsável em redigir a Cotação Moral dos Filmes, coluna que indicava filmes e impunha normas de como a população deveria assistir um filme. Mas, por outro lado, o Cine Clube tornava acessível a veiculação de filmes produzidos em países como Rússia, Polônia ou Alemanha para as pessoas da cidade.

Partindo da análise das matérias nos jornais, perce- 
bemos que o cinema era uma das principais atividades de lazer dos jovens hamburguenses na década de 1960. Percepção que foi confirmada a partir das falas dos depoentes que serão listadas a seguir e que irão contribuir para contarmos um pouco da influência do cinema nos jovens do período selecionado.

\section{0 cinema pela fala dos seus frequentadores}

O cinema em Novo Hamburgo começou em 1913, quando Adão Adolfo Schmitt alugou o salão de sua casa no bairro Hamburgo Velho para a projeção de filmes. Anos mais tarde, a assídua frequentadora de cinema Sara Lanzer, mandou construir uma sala de projeções, depois de ganhar um prêmio na loteria. Esta sala recebeu o nome de Cinema Central, e após ser comprado por Lothário Blankenheim na década de 40, recebeu o nome de Cine Aída ${ }^{3}$.

\section{Com tantas salas concentradas} em uma cidade emancipada em 1927, na década de 1960, 0 cinema era um programa comum, conforme mencionado em todas as entrevistas realizadas.

Na década de 1930, surgiu no centro de Novo Hamburgo o Cinema Guarani, da empresa Jaeger \& Venturini Ltda., que nos anos 50 construíram, também no centro, o Cine Lumière, e na década de 1960, o Cine Avenida. Nesse período já havia o Cine Theatro Carlos Gomes que era propriedade da família Blankenheim. No início dos anos 60, o Carlos Gomes teve seu nome alterado para Saionara. José Carlos Blankenheim, um de nossos entrevistados, foi o último representante da família que esteve à frente do cinema, nos anos 1990. Segundo ele, o cinema, desde o seu início, era um acontecimento de grande relevância na sociedade local:

Pegava, usava uma roupa especial e ia para o cinema. [...] Porque aquilo era um evento social. Tinha gente que se conhecia no cinema, namoravam no cinema, se um cara morava num bairro, o outro no outro eles se encontravam no cinema. [...] O cinema sempre foi uma coisa muito forte ${ }^{4}$.

Com tantas salas concentradas em uma cidade emancipada em 1927, na década de 1960, o cinema era um programa comum, conforme mencionado em todas as entrevistas realizadas. A depoente Sigrid relata que "em solteira nós íamos 3 a 4 vezes por semana. Porque não tinha outra coisa, né? Era o lazer que a gente tinha" ${ }^{\prime 5}$. A entrevistada Hedviges conta, com humor, que ia tanto ao cinema, que no nascimento de três de suas quatro filhas o trabalho de parto iniciou lá mesmo. Ela fala ainda sobre as roupas usadas para ir ao local, que eram normalmente as mais bonitas do seu armário.

Tem pessoas até hoje que quando falam comigo dizem que nunca vão esquecer um dia que eu fui ao cinema com um mantô azul turquesa (risos) que eu entrei no cinema todo mundo olhou. Eu era loira e coisa e dai achavam que eu era bonitinha. Eu disse ai eu não vou esquecer nunca to entrando no cinema Carlos Gomes com aquele mantô azul turquesa, a gente se produzia toda, porque era única coisa ${ }^{6}$.

Sigrid também comenta sobre as roupas usadas para ir ao cinema:

A gente botava uma roupa de sair, roupa bonita, de festa. Não era calça jeans, nem tinha. Era roupa bonita, roupa de festa. A gente arrumava o cabelo especialmente para ir ao cinema. Os homens geralmente iam de fatiota, de terno ${ }^{7}$.

As salas de cinema eram, então, lugares para ver e ser visto. Os filmes serviam ainda de inspiração para outras atividades. O entrevistado Paulo relata experiências que realizava com seus amigos na infância, influenciadas pelos filmes que assistiam:

Nós montávamos cenas de filmes que tinham impactado mais e fazia naquele papel vegetal. Cortava em tiras compridas e ia emendando as tiras, e ia desenhando os quadrinhos e ele fazia a seqüência de imagens que tu depois desenvolvia numa certa velocidade. Aí a imagem se mexia. Aquilo era um assunto assim que inclusive a minha mãe e a minha vó que sentavam pra assistir as outras tias todas em volta, elas se surpreendiam como é que nós, uns guris de 12, 13 anos, poderíamos chegar ao ponto de reconhecer a técnica. [...] Tu levava uma semana das férias fazendo, e um dia passando aquilo. E, bom, ai tinha duas sessões, essa parte aí tu não grava, (risos) a sessão dos desenhos, e a sessão das mulheres sem roupa. [...] E aí era proibido pra menores de 18 anos (risos) e aí nós assistíamos a sessão ${ }^{8}$.

O depoente Paulo percebe a importância que o cinema tinha para sua vida, não somente como atividade de lazer, mas como fonte de inspiração:

Falando isso pra vocês agora, eu tô me dando conta que tu transportavas o cinema pras tuas idéias e pra 
tua imaginação, o que havia te impressionado mais no cinema. Imagina se naquela época tu tivesses visto esses filmes de hoje, esses efeitos especiais9.

\section{Sedução do cinema e a construção de novas realidades}

Os filmes projetados nas salas de cinema traziam os espectadores para uma realidade diferente daquela em que viviam. Possibilitavam às pessoas conhecer um mundo diferente daquele vivido na cidade, tornando a ida ao local uma prática. Canevacci (1984) afirma que o cinema seduz, e coloca que:

a partir do momento da aquisição dos ingressos coloridos e de sua divisão pela metade na passagem crucial da entrada, que simboliza a diferença entre o dentro e o fora [...] formaliza-se o momento mágico de iniciação (Canevacci, 1948, p.130).

Dumazedier (2000) apresenta as razões que ele acredita levarem as pessoas a irem ao cinema. Entre elas, diz que:

A maior parte dos indivíduos interrogados procura no cinema uma vida imaginária. Esses indivíduos, ao apresentarem essa versão, dão um sentido mais preciso e rico à sua participação no espetáculo cinematográfico [...] Parece que o público procura mais aquilo que Lefebvre chama de "imagem inversa da vida cotidiana" (Dumazedier, 2000, p.170).

Para o autor, as pessoas, ao participarem do espetáculo cinematográfico, procuram encontrar uma liberação, ao mesmo tempo em que buscam um passatempo, assim encontrando uma de suas formas de lazer. A entrevistada Mariene relata que percebe que o cinema influenciou positivamente a sua vida, seja buscando reviver os momentos das películas assistidas ou vestindo-se como as atrizes e imaginando-se no seu lugar: "[...] o sonho e a imaginação nos conduziam para uma vida melhor" ${ }^{\prime \prime}$.

\section{Os gêneros preferidos dos jovens}

No início da década de 1960, a variedade de gêneros de filmes nos cinemas de Novo Hamburgo não era muito grande, conforme relata a entrevistada Joana: "olha, tu tinha duas escolhas na época: o filme de Tarzan, de faroeste, ou musicais mais românticos. É óbvio que eu gostava mais desses (risos)"11.

Todas as entrevistadas do sexo feminino demonstraram preferência pelos filmes românticos, citando atrizes que se tornaram famosas por este gênero. Os homens demonstram gostar dos filmes de ação, como faroeste, mas lembram-se bem dos seriados que assistiam quando crianças no cinema. Mas como muitas vezes acompanhavam as moças às salas de projeção, guardam boas lembranças dos filmes românticos também, como conta Paulo:

Varia conforme a idade (risos), porque bem no início eram seriados, aí tinha o [...] Durango Kid, Zorro, esse gênero de faroeste, bandido e mocinho tipo assim. Aí houve uma época que estava em voga muito o Capitão Marvel, ele tinha muito filme. [...] Depois do Capitão Marvel, daí eu acho que entrou o período do [...] dos namoros, da puberdade já, aí os românticos faziam mais o tipo. Doris Day, Marilyn Monroe foi bem no fim, mas antes disso tinha [...] puxa vida como é aquela morena [...] Mas era uma série de atrizes, a que foi princesa de Mônaco, Katherine Hepburn, aquela francesa Brigitte Bardot foi a primeira que nós vimos sem roupa ${ }^{12}$.

Sobre os filmes favoritos, todos os entrevistados comentam sobre os filmes internacionais, em especial os americanos são os mais lembrados. Hedviges comenta: "olhávamos somente filmes internacionais. Nacionais nós nunca fomos assistir. Naquela época eu acho que nem existiam filmes nacionais, foi bem mais tarde".

\section{A influência dos atores americanos no modo de vestir e agir dos hamburguenses [...] comprova a tendência da população a preferir estes filmes, e a ignorar grande parte das produções nacionais.}

O Jornal NH, em uma reportagem na qual entrevista duas moças, publica que "as moças entrevistadas, não fugindo a regra geral, conhecem pouco cinema nacional". Zilda fala que o brasileiro explora sexo de maneira pornográfica. Betti consegue se recordar apenas de uma nacional bom, O Pagador de Promessas ${ }^{13}$.

A influência dos atores americanos no modo de vestir e agir dos hamburguenses, conforme descrito a seguir, comprova a tendência da população a preferir estes filmes, e a ignorar grande parte das produções nacionais.

\section{0 cinema nas roupas, no cabelo e nas atitudes}

Os filmes exerciam uma grande influência na vestimenta dos frequentadores de cinema no período pesquisado. Todas as entrevistadas do sexo feminino afirmaram ser influenciadas pelas vestimentas das 
atrizes dos filmes. Anny Bertrudes ${ }^{14}$ conta que elas procuravam se vestir de acordo com os filmes porque eram eles que ditavam o que era ou não era moda, já que eram a única fonte de conhecimento sobre o que estava na moda em outros lugares. Hedviges explica:

Quando apareceu a Marilyn Monroe cortei meu cabelo igual, tudo igual, vestia até aquela roupa justa, apertadinha, aquela saia bem apertada (risos) Tanto é que achavam que eu era parecida com a Marilyn Monroe. Porque eu imitei ela. As minhas amigas também o faziam ${ }^{15}$.

A entrevistada Terezinha conta que buscava costureiras que fizessem roupas para que ela se sentisse como uma artista. Joana relata uma situação em que se lembra da influência de uma roupa específica sobre as moças de Novo Hamburgo:

Houve uma época que a Brigitte Bardot influenciou bastante. Um vestido xadrezinho com um babado aqui assim (aponta pro peito), com renda de broderí e um babado embaixo. E daí foi assim, aquele verão, todo mundo usou vestidos daquele padrão. Porque era uma coisa diferente. Então o pessoal comprava roupa, ia na costureira e copiava bastante ${ }^{16}$.

Os homens também começaram a arrumar mais o cabelo e vestir-se de acordo com o que viam nas películas. Os cabelos também sofreram influência, conforme uma coluna no Jornal NH: "temos de olhar duas vezes para ter a certeza de que estamos deparando com uma pessoa do sexo masculino, tal a semelhança que ficam com o cabelo lambidinho para o lado tipo língua de vaca"17.

As estrelas da época eram vistas e ambicionadas por todos, segundo Morin (1989) a estrela é um padrão-modelo para as pessoas, pois determina tanto a aparência exterior quanto os comportamentos. Para ele, as pessoas "sonham com Rita Hayworth e representam seus papéis nos seus sonhos" (Morin, 1989, p.41).

As estrelas dos filmes representavam papéis que tinham posições admiradas e sonhadas pelos hamburguenses. "As estrelas conduzem nossos atos, gestos, poses, atitudes [...], jeito de acender um cigarro, de soltar a fumaça, de beber com naturalidade ou com sex-appeal, de cumprimentar" (Morin, 1989, p.52).

Algumas pessoas tentavam uma proximidade real com essas estrelas, como a entrevistada Verena: "A gente mandava uma correspondência pra Hollywood e recebia as fotos deles autografadas. Tinha a Marilyn Monroe. Eu gostava muito da Rita Hayworth, Elizabeth Taylor. Eram muito bonitas"18. Já a depoente Joana ${ }^{19}$, que residiu por um ano nos Estados Unidos, conta: "sabe que quando eu fui para lá, as pessoas, quando eu voltei, pediam "tu viu algum artista de cinema? (risos). Que nem o pessoal que vem da Europa pro Brasil: "tu viu macacos"?

Conforme mostram as entrevistas, o cinema era a principal porta de entrada das tendências e novidades, pois não existiam fontes como a televisão dos dias de hoje, e as revistas ainda eram raridade.

\section{As memórias da juventude vindas das telas}

Com a análise das matérias do Jornal $\mathrm{NH}$ e das memórias reconstruídas pelas entrevistas que seguiram a história oral, podemos chegar a algumas reflexões ao considerarmos o cinema como parte do cotidiano e uma prática de lazer dos jovens da década de 60, em Novo Hamburgo.

Foram percebidos muitos pontos em comum na fala dos entrevistados, e que os discursos se repetiam, enfatizando a influência do cinema em suas vidas. Eles, ao se sentirem fascinados com o que viam nos filmes, buscavam se vestir e agir como seus ídolos, encontrando nas salas de projeção uma janela para um mundo exterior. Dumazedier (2000) coloca que o cinema determinou transformações no comportamento e nas atitudes com relação aos lazeres diários e da vida cotidiana e da juventude do mundo inteiro.

Fica perceptível ainda a relação entre as memórias individuais dos depoentes com uma memória coletiva. Foi comum entre os entrevistados a utilização da primeira pessoa do plural, o "nós", admitindo a ligação de suas lembranças com outras, de familiares, amigos de infância, cônjuges, etc., indo ao encontro das concepções de Halbwachs (2006) quando este afirma que a memória individual somente existe a partir de uma memória coletiva.

O cinema projetou novos mundos para aquela localidade. Verificamos que as pessoas que viveram essas experiências guardam ainda as imagens dos ídolos e atualizam em suas memórias as lembranças das salas de cinema como locais de sociabilidade. Essa é a verdadeira magia do cinema, projetar imagens que não ficam marcadas somente nas telas, mas que influenciam o comportamento e os costumes de diversos públicos, não importando onde essas pessoas estejam $\square$ FAMECOS

\section{NOTAS}

1 Novo Hamburgo é uma cidade da região metropolitana de Porto Alegre, capital do estado do Rio Grande do Sul, Brasil.

2 Este trabalho é parte do projeto de pesquisa "O doce nada fazer: um estudo sobre lazer e identidade(s) em Novo Hamburgo" do grupo de pesquisa Cultura e Memória da Comunidade, do Centro Universitário Feevale. Esse artigo teve a participação de Vitória Fischer Schilling, acadêmica do curso de 
Comunicação Social - Habilitação em Jornalismo do Centro Universitário Feevale e bolsista FAPERGS de iniciação científica do projeto "O doce nada fazer": Um estudo sobre lazer e identidade(s) em Novo Hamburgo.

3 As informações a respeito do início do cinema em Novo Hamburgo relatadas nesse artigo foram retiradas da reportagem "Sessões históricas no início do século", Jornal NH, 04 fev 2000, p.4.

4 Entrevista com José Carlos Blankenheim. Abr 2008.

5 Entrevista com Sigrid Esther Schilling. Mar 2008.

6 Entrevista com Hedviges Terezinha Erkens Fischer. Mar 2008.

7 Entrevista com Sigrid Esther Schilling. Mar 2008.

8 Entrevista com Paulo Reichert. Mai 2008.

9 Entrevista com Paulo Reichert. Mai 2008.

10 Entrevista com Mariene Weissheimer. Jul 2008.

11 Entrevista com Joana Defferrari. Jul 2008.

12 Entrevista com Paulo Reichert. Mai 2008.

13 Jornal NH, 19 set 1969, p.13.

14 Entrevista com Anny Bertudes Engelmann. Mar 2008.

15 Entrevista com Hedviges Terezinha Erkens Fischer. Mar 2008.

16 Entrevista com Joana Defferrari. Jul 2008.

17 Jornal NH, 16 set 1961, p.8

18 Entrevista com Verena Backes. Jun 2008.

19 Entrevista com Joana Defferrari. Jul 2008.

\section{REFERÊNCIAS}

ALBERTI, Verena. Fontes orais: Histórias dentro da História. In: PINSKY, Carla Bassanezi (Org). Fontes históricas. São Paulo: Contexto, p.155-202, 2005

. Manual de História oral. Rio de Janeiro: FGV, 2006.

BARDIN, Laurence. Análise de conteúdo. Lisboa: Edições
70, 2004.

CANEVACCI, Massimo. Antropologia do cinema. São Paulo: Brasiliense, 1984.

DUMAZEDIER, Joffre. Sociologia empírica do lazer. São Paulo: Perspectiva, 1979.

HALBWACHS, Maurice. A memória coletiva. São Paulo: Centauro, 2006.

MORIN, Edgar. As Estrelas: mito e sedução no cinema. Rio de Janeiro: José Olympio, 1989.

SELBACH, Jefferson Francisco. Novo Hamburgo 19271997: os espaços de sociabilidade na gangorra da modernidade. Porto Alegre, 1999. 416 f. Dissertação (Mestrado em Planejamento Urbano e Regional). Universidade Federal do Rio Grande do Sul UFRGS/ Faculdade de Arquitetura.

PUHL, Paula Regina \& SILVA, Cristina Ennes da. Minha mãe mandou eu escolher esse daqui! Um estudo sobre as preferências e o significado do esporte e do lazer em Novo Hamburgo (1960/2000). In: Lecturas, educación física y deportes revista digital. Buenos Aires - Año 13 - n 121 - Jun de 2008. Disponível em: <http://www. efdeportes.com/efd121/significado-do-esportee-do-lazer-em-novo-hamburgo.htm>

TRAQUINA, Nelson (Org.). Jornalismo: Questões, teorias e "estórias". Lisboa: Veja Editora, 1999.

WOLF, Mauro. Teorias da comunicação. Lisboa: Editorial Presença, 2001. 